\title{
Editorials
}

\section{Out of hours and primary care:}

\author{
closer and closer apart
}

Although responsibility for out-of-hours $(\mathrm{OOH})$ general practice care (provided between $6.30 \mathrm{pm}$ and $8 \mathrm{am}$ and on weekends and public holidays) changed substantially in 2004, the same GPs who had previously provided this care often continued as the clinical mainstays of the service. Before 2004, patients were often seen $\mathrm{OOH}$ by their own GP, or at least a GP they knew from their practice, but this continuity has now been lost and has led to a lack of confidence and trust in $\mathrm{OOH}$ services, reflected in a greater propensity for patients to complain and to concerns about patient safety. ${ }^{1}{ }^{12}$ Primary care now needs to rise to the challenge of reengaging with $\mathrm{OOH}$ care in the context of rising patient demands and expectations, and the imperatives of patient safety and clinical governance.

\section{SHIFTING FROM LOCAL CARE}

Most GPs working in $\mathrm{OOH}$ services cover much larger geographical areas than previously when cover was limited to the practice area or a GP cooperative of several practices. The involvement of local GPs who know the area and the local health services remains important, not least for patient safety. Lack of such knowledge appears to have contributed to $\mathrm{OOH}$ errors in the past. ${ }^{3}$ The model of $\mathrm{OOH}$ services run by less experienced GPs, with the best trained and most experienced concentrating their efforts on daytime care in the surgery is not one that most $\mathrm{OOH}$ providers would like to see, although it is probably a reality in some areas. ${ }^{4}$ While it is no longer possible for many GPs to take a major role in $\mathrm{OOH}$ care, most have a keen interest in the quality of $\mathrm{OOH}$ care provided to their patients, and need to be involved in the assessment, monitoring, and regulation of $\mathrm{OOH}$ services. ${ }^{5}$ In the past, such involvement has been minimal, and monitoring mechanisms have been patchy in their effectiveness. ${ }^{6}$ Primary care now needs to change this situation, because the landscape has changed.

The 'rota organising clubs' of the old days have now evolved into complex organisations that have to match capacity to demand, monitor performance standards, and developing robust clinical governance procedures. ${ }^{7}$ Many are also developing their own education programmes centring on important areas in $\mathrm{OOH}$ care, such as telephone consultations and palliative care.

\section{INTEGRATION}

$\mathrm{OOH}$ providers are now benchmarking their performance against other $\mathrm{OOH}$ care providers in a drive to raise standards. Commissioners are being urged to support $\mathrm{OOH}$ providers to become a valued and integral part of the local health community'. ${ }^{6}$ But to improve quality, forge links with other services, and develop services further, $\mathrm{OOH}$ providers need some semblance of a long-term strategy. This is impossible if, as is the case of the majority of $\mathrm{OOH}$ providers, contracts are so short lived, lasting as little as 3 years in some cases. Often this is done because of the wish to change providers when costs rise, but it also means that time and expense are taken up preparing tenders, diverting resources that could be used to improve services. In this regard we are now repeating the mistakes of the past when in 2004, despite TUPE (Transfer of Undertakings [Protection of Employment]), the new services replacing the previous cooperatives, started at a disadvantage due to loss of key players and lack of continuity.

\section{COST OF OOH CARE}

Of course there should be regular and robust monitoring and a shared push for improved quality of services, but constant change for reasons of cost alone is counterproductive. Many providers would prefer a more involved commissioner, especially with GP involvement, with a consistency of approach and project management. GPs, with their understanding of the importance of longterm investment in developing practices, should push for greater understanding of the importance of this.

Commissioners should also remember that the cheapest is not necessarily the best (and nor is the most expensive). As Colin Thomé points out, cheap $\mathrm{OOH}$ services often find it difficult to attain National Quality
Requirements (NQRs) and a good $\mathrm{OOH}$ service adds value to the wider health community with fewer referrals to hospitals and reduced secondary care costs. ${ }^{6}$ Current $\mathrm{OOH}$ care is seen by some as more expensive and less efficient. ${ }^{8}$ In fact the increased costs reflect the true price of providing the service and are inevitably higher, because of the poor remuneration GPs received before 2004 . This was a point not lost on the government who found that the financial situation after 2004 changed radically.

We know there is a wide disparity in demand and therefore in costs in areas with similar demographics. ${ }^{7}$ In much the same way as providers, many practices with similar demographics seem to have differing $\mathrm{OOH}$ use and we need further research to find out why this occurs and what could and should be changed. An example of this can be seen in the demand for repeat prescriptions at weekends which can constitute as many as $20 \%$ of calls to our service at Mastercall Healthcare on a Saturday morning. Issuing of repeat prescriptions also highlights questions about how we define the services provided in $\mathrm{OOH}$.

\section{OPTIMISING OOH CARE}

The 'handover' of responsibility in 2004 from practices to primary care trusts was accompanied by a lack of clarity about what the new services were to provide. Are we providing an urgent service which only treats emergencies (the definition of which may well, like beauty, be in the eye of the beholder) or an unscheduled care service treating anything? We should be careful about blaming patients for 'unnecessary' use of an $\mathrm{OOH}$ service if the commissioners have yet to grasp the nettle of deciding exactly what we should be providing.

The main concern of many GPs seeking to work for us is the lack of prior information they have when they see a patient. This can lead to unnecessary admissions, treatment and, more importantly, a reduced quality of

\section{"Cheap OOH services often find it difficult to attain National Quality Requirements and a good $\mathrm{OOH}$ service adds value to the wider health community.}




\section{"We should be careful about blaming patients for 'unnecessary' use of an $\mathrm{OOH}$ service if the commissioners have yet to grasp the nettle of deciding exactly what we should be providing.}

care for the patient. This is especially important in the care of palliative care patients where the transfer of good quality information is vital in reducing unnecessary referrals and admissions and promoting a seamless high quality care. ${ }^{10}$ Reliable methods of shared communication should be high up on the list of requirements for any review of $\mathrm{OOH}$ services by our new GP commissioners.

Even though primary care no longer has responsibility for 24 -hour care, it still has a duty to see that patients get the best quality $\mathrm{OOH}$ care. Better relationships between clinicians, commissioners, and $\mathrm{OOH}$ providers will go some way to securing the better continuity of care we all seek to achieve for all our sakes.

\section{John O'Malley,}

Medical Director, Mastercall Healthcare, Stockport.

\section{Provenance}

Commissioned; not externally peer reviewed.

DOI: 10.3399/bjgp12X635976

\section{ADDRESS FOR CORRESPONDENCE}

\section{John O'Malley}

Mastercall Healthcare, 226-232 Wellington Road South, Stockport, SK2 6NW, UK.

E-mail: jomal96@aol.com

\section{REFERENCES}

1. Commission on Generalism. Guiding patients through complexity: modern medical generalism. Report of an Independent Commission for the Royal College of General Practitioners and The Health Foundation. London: RCGP and the Health Foundation, 2011

http://uww.rcgp.org.uk/pdf/COMMISSION\%2ORE PORT\%200N\%20MEDICAL\%20GENERALISM\%2 0_rev_7\%200CTOBER\%202011.pdf laccessed 7 Mar 2012)

2. House of Commons Committee of Public Accounts. The provision of out-of-hours care in England; sixteenth report of session 2006-07. London: TSO, 2007.

3. Cosford PA, Thomas JM. Safer out of hours primary care. BMJ 2010; 340: $\mathrm{c} 3194$.

4. Jones R. Should general practitioners resume 24 hour responsibility for their patients? Yes. BMJ 2007; 335(7622): 696 .

5. Campbell JL, Clay JH. Out-of-hours care: do we? Br J Gen Pract 2010; 60(572): 155-157.

6. Colin-Thomé DC, Field S. General practice outof-hours services. Project to consider and assess current arrangements. London: Department of Health and RCGP, 2010. http://www.dh.gov.uk/prod_consum_dh/groups/d h digitalassets/dadh/den/daps/documents/digital asset/dh_111893.pdf (accessed 7 Mar 2012).

7. Primary Care Foundation. Improving out of hours care: what lessons can be learned from a national benchmark of services? East Sussex: Primary Care Foundation, 2010

http://www.primarycarefoundation.co.uk/files/Pri maryCareFoundation/Downloading_Reports/Rep orts_and_Articles/National_Out_of_Hours_Benc hmark/Improving_OOH_Care_Lessons_from_tw o_benchmarks_RELEASE.pdf laccessed $7 \mathrm{Mar}$ 2012

8. Heath I. Out of hours primary care - a shambles? BMJ 2007; 334(7589): 341 .

9. O'Dowd A. Cost of out of hours care was $22 \%$ higher than predicted in England. BMJ 2006; 332(7550): 1113

10. Harris DG, Owen RE, Finlay IG. Delivery of safe and effective care out of hours: the impact of the shared clinical record on a patient's out-of-hours contact with specialist palliative care. Clin Med 2011; 11(1): 92-93 